\title{
Autobiografia orientada para avaliar vida, carreira e planejar para a aposentadoria ${ }^{1}$
}

\author{
Lucia Helena de Freitas Pinho França ${ }^{2}$ \\ Silvia Miranda Amorim \\ Andreia Pereira de Souza \\ Thais Cravo Schuabb \\ Universidade Salgado de Oliveira, Niterói-RJ, Brasil
}

\section{Resumo}

O processo de envelhecimento populacional requer urgência na revisão das diretrizes e práticas organizacionais, como os Programas de Preparação para a Aposentadoria (PPA). Pesquisa recente sobre PPA no Brasil concluiu que é preciso priorizar a sustentabilidade, consistência metodológica e avaliações para confirmar a eficácia desses programas. O objetivo deste estudo foi apresentar e discutir a aplicabilidade da Autobiografia Orientada (GAB) como método inovador para o planejamento e decisão da aposentadoria. O texto discute a relevância do PPA, os métodos utilizados, princípios e a operacionalização da GAB, sugerindo um roteiro básico para conduzir a avaliação da vida, carreira e os recursos para aposentadoria. Conclui-se que a GAB é uma ferramenta adequada para o planejamento e tomada de decisão na aposentadoria.

Palavras-chave: Aposentadoria, tomada de decisão, autobiografia, planejamento

\section{Abstract: Guided Autobiography to assess life, career and plan for retirement}

The aging population process requires urgency in reviewing organizational guidelines and practices, such as the Retirement Preparation Programs known as PPA. A recent research regarding PPA in Brazil concluded that priority should be given to sustainability, methodological consistency and evaluations to confirm the effectiveness of these programs. The purpose of this study was to present and discuss the applicability of the Guided Autobiography $(\mathrm{GAB})$ as an innovative method to evaluate life, career and resources for retirement. The text discusses the relevance of the PPA, used methods, GAB principles and procedures, suggesting a basic guide for conducting life, career and retirement resource assessment. In conclusion, the GAB seems a suitable tool for planning and decision making in retirement.

Keywords: Retirement; decision making; autobiography; planning

\section{Resumen: Autobiografía orientada para evaluar vida, carrera y planear la jubilación}

El proceso de envejecimiento poblacional requiere urgencia en la revisión de directrices y prácticas organizativas, como Programas de Preparación para la Jubilación (PPA). Un estudio reciente sobre los PPA en Brazil concluyó que es necesario priorizar la sostenibilidad, consistencia metodológica y evaluaciones que confirmen la eficacia de estos programas. El objetivo de este estudio fue presentar y discutir la aplicabilidad de la Autobiografía Orientada (GAB) como método innovador para evaluar la vida-carrera y resources para la jubilación. El texto discute la relevancia de PPA, métodos utilizados, principios e operacionalización de la GAB, sugiriendo un itinerario básico para evaluar vida, carrera y recursos para jubilación. Se concluye que la GAB es una herramienta adecuada para tomar decisión e planear la jubilación.

Palabras clave: Jubilación; tomar de decisión; autobiografía; planificación

\footnotetext{
${ }^{1}$ A primeira autora agradece à FAPERJ pelo apoio recebido às pesquisas realizadas sobre avaliação dos programas de preparação para a aposentadoria entre 2014-2016. Thais Cravo Schuabb e Silvia Miranda Amorim agradecem, respectivamente, por bolsa de mestrado e doutorado concebidas pela CAPES.

${ }^{2}$ Endereço para correspondência: Rua Marechal Deodoro, 217, Centro, 23030-060, Niterói, RJ. E-mail: lucia.franca@gmail.com
} 
"Revisar ou relembrar a vida é um processo essencial à trajetória dos adultos idosos.” (Birren, 2001)

Até 1960 a expectativa de vida no Brasil estava em torno dos 54 anos de idade (Banco Mundial, 2016), e as pessoas viviam poucos anos sem trabalhar após a aposentadoria. Entretanto, os avanços tecnológicos e da medicina causaram a melhoria das condições de saúde e saneamento, provocando um rápido aumento da expectativa de vida que atualmente é de 75,8 anos de idade (Instituto Brasileiro de Geografia e Estatística [IBGE], 2017). Como consequência da mudança demográfica, é possível concluir que as pessoas estão vivendo aproximadamente 20 anos na condição de aposentados.

O processo de envelhecimento populacional é uma tendência mundial e a necessidade de práticas organizacionais específicas sobre o tema foi reconhecida pela Organização Mundial de Saúde (OMS, 2015) nas assembleias mundiais de envelhecimento realizadas em Viena (1982) e em Madrid (2002). Com o apoio da Organização das Nações Unidas, do Banco Mundial e de outras organizações, as recomendações dessas reuniões apontaram na direção da criação de políticas que incorporem uma nova compreensão do envelhecimento em todas as gerações e que garantam a mobilidade, a independência e a saúde dos trabalhadores e aposentados à medida que envelhecem. Por parte das ações a serem propostas pelas organizações, foram estimuladas práticas como a atualização dos trabalhadores mais velhos, a implantação de horários flexíveis de trabalho, a redução dos preconceitos quanto à idade (ageismo ou idadismo) e a harmonia nas equipes intergeracionais, bem como a promoção dos programas de preparação para a aposentadoria para aqueles que desejam ou precisam sair do mercado de trabalho (França \& Soares, 2009).

Contudo, apesar dos movimentos internacionais descritos, bem como a Política Nacional do Idoso (1994) e o Estatuto do Idoso (2003) que recomendam algumas das ações citadas acima, essas não parecem ter tido a repercussão esperada na percepção dos gestores sobre o envelhecimento no contexto organizacional brasileiro (França et al., 2014). Em um estudo realizado com 207 empresas de todo o país, França et al. (2014) constataram que, apesar de a maioria dos gestores entrevistados considerar a importância do PPA, apenas 23\% das empresas de fato implementavam o programa. Além disso, das empresas que realizavam o PPA, poucas realizavam acompanhamento ou avaliação após a saída do aposentado da empresa, o que evidencia a necessidade de se repensar, desenvolver e ampliar ainda mais as possibilidades para o PPA no cenário brasileiro (França et al., 2014).
É preciso ressaltar que a redução da taxa de natalidade e o aumento do número de idosos no Brasil trazem um desafio para o governo brasileiro, no que se refere ao sustento daqueles que se aposentam, ao mesmo tempo em que o mercado de trabalho requer, com a diminuição da natalidade, a presença de profissionais mais experientes (França, 2016). Além disso, o trabalho é o papel de referência na vida dos indivíduos, inclusive ao servir como base do reconhecimento de si próprio no mundo e de intermediação das suas relações com o meio (Boehs, Medina, Bardagi, Luna, \& Silva, 2017). Portanto, os governos e as organizações de trabalho precisam repensar o envelhecimento, quer na manutenção e inclusão do trabalhador mais velho no mercado, quer na inclusão de programas de planejamento para a aposentadoria.

Há diversas formas de se perceber a aposentadoria. Por um lado, a aposentadoria pode representar um novo começo, com mais tempo para relacionamentos familiares e sociais e atividades culturais e de lazer, que antes eram desenvolvidas praticamente apenas nos finais de semanas ou férias. Sendo, então, uma possibilidade de mudança de estilo de vida, em que o trabalho permanece existindo, porém sem o compromisso e pressão anteriores, podendo ser utilizado para ajudar o próximo ou a sociedade ou concretizando um sonho de toda uma vida (França \& Vaughan, 2008). Por outro lado, essa percepção não é unânime; sendo percebida por alguns como momento de crise.

Nessa perspectiva, vale ressaltar a visão da aposentadoria como um estágio do desenvolvimento de carreira que considera o potencial contínuo de crescimento e renovação das pessoas e acredita que esse pode ser um momento no qual os aposentados têm a possibilidade de alinhar suas prioridades de carreira, conciliando o trabalho e as atividades de lazer (Wang \& Shi, 2013). Rafalski e Andrade (2017) e Wang e Shi (2013) destacam que esse processo depende das capacidades físicas e cognitivas individuais, como maneira positiva ou negativa de perceber o momento, bem como das características do trabalho e dos fatores organizacionais, como o clima organizacional.

Wang e Shi (2013) ressaltam ainda que a extensão da carreira é um movimento cada vez mais presente em nossa sociedade, devido às mudanças no sistema de aposentadoria, ao desenvolvimento da tecnologia e ao afastamento das tradicionais carreiras lineares. O Instituto de Pesquisa Econômica Aplicada - IPEA (2016) apontou que o grau de participação dos trabalhadores mais velhos no mercado de trabalho no Brasil foi avaliado como alto no período entre 1992 a 2012, quando comparado a outros países. Segundo o IPEA (2016), entre os principais motivos apontados para esse aumento estão: o complemento da renda, 
a aposentadoria muito cedo, a boa condição de saúde, a sociabilidade no ambiente de trabalho.

Face à complexidade dos fatores relacionados ao momento da aposentadoria, é importante a avaliação da trajetória da carreira e a realização do planejamento para a aposentadoria (Froidevaux, Baumann, Maggiori, Wieber, \& Rossier, 2017; Taylor \& Schaffer, 2013). A preparação, orientação ou educação para a aposentadoria consideram a tomada de consciência ou reflexão que incentiva a descoberta de potencialidades e a busca de novas áreas de interesse (Zanelli et al., 2010; Zanelli, 2012).

França et al. (no prelo), em uma avaliação de programas de preparação para a aposentadoria em 44 organizações, concluíram que não há a adoção de um método especifico que inclua o acompanhamento e avaliação dos aposentados em função dos objetivos do programa. Foi observada ainda a falta de continuidade do PPA nas instituições, quer por falta de recursos, ingerência política, ou por desinteresse da organização nesta temática, desconsiderando, assim, o cumprimento da legislação que estabelece a existência desses programas em pelo menos um ano antes da data de aposentadoria dos trabalhadores.

Considerando a relevância do planejamento para a aposentadoria e a carência das organizações em estabelecer um método de PPA que mensure a eficácia e a sustentabilidade desta ação nas organizações, esse estudo teve por objetivo apresentar e discutir a aplicabilidade de um método inovador que possibilite a avaliação da carreira e a preparação para a decisão de se aposentar ou continuar trabalhando na aposentadoria.

De forma a contextualizar o leitor ao assunto, este estudo teórico é separado em três partes. A primeira aborda a importância do planejamento para a aposentadoria como estratégia de desenvolvimento nas organizações. A segunda apresenta a Autobiografia Orientada, que se trata de um método de revisão da vida desenvolvido para a maturidade pelo gerontólogo James Birren (Birren \& Deutchman, 1991; Birren \& Feldman, 1997). A última parte discute a aplicabilidade da Autobiografia orientada como uma ferramenta aplicada a contextos de trabalho e aposentadoria.

\section{Planejamento para a Aposentadoria}

A aposentadoria depende de diversos aspectos individuais, culturais e sociais, uma vez que nem todos os que vão se aposentar conseguem se imaginar distantes de suas funções, sem o convívio diário com os colegas, eventos e viagens, salários e benefícios, senso de ocupação e até a rotina que o trabalho proporciona. A prioridade dada ao trabalho por alguns trabalhadores pode tornar a sua aposentadoria mais difícil, provocando uma sensação de falta de propósito e incapacidade de administrar seu tempo livre (França et al., 2013; França \& Vaughan, 2008; Zanelli, Silva, \& Soares, 2010; Zanelli, 2012).

O planejamento é considerado o primeiro passo do processo de aposentadoria. Nessa etapa, os trabalhadores exploram e consideram as diversas questões pertinentes ao momento, como onde viver, como manejar seu tempo e como criar uma nova identidade (Wang \& Shi, 2013). Somente após essa etapa devem ser tomadas as decisões relacionadas a se aposentar ou dar continuidade na carreira e a se ajustar às mudanças consequentes dessas decisões (Froidevaux et al., 2017). Quando realizado de maneira eficaz, o planejamento tende a facilitar o ajustamento e as reações afetivas, influenciando o desenho da experiência da aposentadoria em longo prazo (Taylor \& Schaffer, 2013). França et al. (2013) assinalam que é preciso se planejar para a decisão e, nesse processo decisório, estão envolvidas diversas variáveis, quer relacionadas aos recursos individuais (idade, tempo de aposentadoria, nível socioeconômico, etc.), aos relacionados ao trabalho (satisfação com o trabalho, controle do trabalho, flexibilidade, e outros) ou aos aspectos sociais e de relacionamento (atividades de lazer, relacionamentos familiares, afetivos, amizades, e outros). O planejamento deve ser considerado também após a decisão, tendo por base os recursos que cada futuro aposentado dispõe e o que ainda é preciso realizar para que ele possa ter o bem-estar na aposentadoria.

França e Soares (2009) enfatizam que o planejamento deveria ser um processo engajado à educação ao longo da vida, que consiste no aprendizado formal (escolas, instituições de treinamento, universidades), no aprendizado não formal (treinamento nas instituições) e no treinamento informal (família e comunidade) da infância à velhice. Porém, a falta de planejamento e perspectiva de futuro, especialmente dos brasileiros, faz com que a decisão por continuar trabalhando, sair do mercado de trabalho ou começar uma nova carreira na aposentadoria seja tomada a curtíssimo prazo, se tornando ainda mais estressante.

$\mathrm{Na}$ tentativa de contemplar a complexidade do indivíduo, o planejamento tem sido abordado em diferentes domínios (França \& Soares, 2009; Zanelli et al., 2010). Yeung (2013) destacou quatro principais domínios de planejamento para aposentadoria: (a) o planejamento financeiro, que é o mais conhecido e realizado pelos pré-aposentados e tem como finalidade desenvolver uma segurança financeira que perdure durante a velhice; (b) o da saúde, que busca manter a saúde física existente antes da aposentadoria, através da prática de atividades física, alimentação saudável e a realização de exames periódicos; (c) o social, que tem como objetivo estabelecer uma rede 
de suporte social, por meio das atividades de interesse do indivíduo, para que possa criar uma nova rede de contatos na aposentadoria e (d) o psicológico, que consiste na adaptação às possíveis mudanças que virão com a aposentadoria, discutindo questões emocionais relacionadas à identidade da pessoa.

Para além da visão tradicional da aposentadoria, as recentes definições de carreira e de aposentadoria consideram que o planejamento não necessariamente irá levar o trabalhador à saída permanente do trabalho. Considerando os vários trajetos que os indivíduos podem seguir na aposentadoria, torna-se necessário que, em um primeiro momento, os trabalhadores obtenham acesso a um maior entendimento do processo decisório da aposentadoria (Kim \& Hall, 2013). Kim e Hall (2013) acreditam que a decisão por uma carreira na idade avançada é influenciada não apenas pela trajetória da primeira carreira, como também por variáveis como habilidades, paixão pelo trabalho, transições e crises superadas anteriormente, bem como um ambiente encorajador.

$\mathrm{Na}$ decisão da aposentadoria, França, Bendassolli, Menezes e Macedo (2013) afirmam que os trabalhadores têm diante de si três opções de escolha: 1. permanecer no mesmo trabalho, com a mesma carga horária e rotina anterior; 2. continuar trabalhando, porém num emprego de horário reduzido, a caminho de uma posterior aposentadoria, o que é denominado bridge employment; ou 3. se aposentar definitivamente. Segundo esses autores, cada decisão a ser tomada é influenciada por diversas variáveis pessoais, como idade, percepção de saúde, relacionamento familiar, situação financeira e fatores do trabalho, como significado atribuído e satisfação.

Nesse sentido, os Programas de Preparação para a Aposentadoria (PPA) podem representar uma chance para os trabalhadores que desejam se aposentar planejem a sua decisão e o processo de transição. O PPA proporciona ainda a identificação de novas opções àqueles que pretendem permanecer no mercado de trabalho (França et al., 2013).

Os PPA se iniciaram no final da década de 1980 quando as grandes organizações, compelidas pela globalização e pelas fusões, precisavam reduzir o número de colaboradores (França, 2016). Seu objetivo era criar o espaço de mudança necessário para a decisão de saída do trabalho. Assim, a maioria desses programas foi implantada por empresas públicas, por meio de seminários com duração de um dia a uma semana em hotéis confortáveis, onde ocorriam palestras sobre saúde, finanças, lazer e empreendedorismo. Sob o efeito da novidade e da volumosa indenização oferecida aos participantes, a avaliação dos programas, baseada na reação imediata ao desfecho do programa, e, de acordo com seus coordenadores, era, em geral, considerada positiva (França, 2016).

Inicialmente, os programas não possuíam uma gama de conteúdos que proporcionassem uma reflexão mais profunda para decisão da aposentadoria, nem tampouco os participantes eram acompanhados durante o processo de transição. Com o tempo, eles foram se ampliando até que a exigência da Política Nacional do Idoso (Brasil, 1994) e do Estatuto do Idoso (Brasil, 2003) estimulou a sua expansão. Há diversas formas de implantar um PPA em uma organização, dependendo prioritariamente das suas intenções, políticas e normas organizacionais. A periodicidade dos programas pode ser de alguns meses ou se estender para dois anos, momento em que ocorrem palestras, grupos de discussão ou mesmo consultorias contratadas pelas organizações para trabalhar com os participantes em workshops e seminários. Os conteúdos geralmente contemplam o âmbito financeiro, de saúde, social e psicológico, como apontado por Yeung (2013), por meio da abordagem de temas considerados importantes para o bem-estar na aposentadoria como planejamento financeiro, promoção de saúde, inserção de novos hábitos de nutrição, exercícios e estilo de vida saudável, diversidade e alocação de tempo para atividades e intensificação de fontes de relacionamentos sociais e familiares (França, 2016; Henkèns et al., 2017).

Apesar da necessidade dos programas e das diversas possibilidades de implantação, são poucas as empresas que oferecem essa oportunidade aos seus funcionários e, quando oferecem, são de maneira similar e pouco personalizada às necessidades do grupo. Existe uma reconhecida importância dos programas por parte dos gestores brasileiros, porém estes ainda estão longe de ser uma prática constante das organizações (França et al., 2014).

A pesquisa de França et al. (no prelo) avaliou o perfil dos PPA realizados em 44 organizações brasileiras. Os resultados demonstraram a ineficiência do estado em colocar em prática a implementação desses programas, especialmente em empresas privadas, visto que existem recomendações, previstas em lei, para que o PPA seja realizado pelo menos um ano antes do trabalhador se aposentar. A maior parte das organizações realiza o PPA utilizando palestras, dinâmicas e vivências. Dentre os conteúdos mais abordados estão a saúde, o aspecto econômico, os relacionamentos familiares e o projeto de vida. Os resultados evidenciaram que, dentre 2.000 empresas pesquisadas, poucas utilizam uma metodologia que possibilite a avaliação do PPA realizado. Além disso, mais raras ainda são aquelas que acompanham o participante na sua aposentadoria, para verificar se o programa alcançou o êxito desejado, especialmente 
quanto ao bem-estar dos seus ex-colaboradores (França et al., no prelo). Vale ressaltar que, mais importante que uma padronização desses programas, é o alinhamento do conteúdo às necessidades dos seus participantes, ou seja, aos fatores que promovem e são relevantes para o bem- estar na aposentadoria (Pazzim \& Marin, 2016). Esse conteúdo pode ser acessado através de pesquisas prévias ao início do programa ou desenvolvido a partir da experiência e conhecimento dos próprios gestores.

A finalidade do PPA é contribuir para que o participante vivencie novas situações, desenvolva habilidades e descubra interesses, sendo capaz de refletir sobre um projeto de vida desejado e os investimentos necessários para alcançá-lo. De acordo com Zanelli et al. (2010, p.53), o projeto de vida é o "processo de construção e de elaboração de ideias, que deve ser continuamente refinado, de modo a transformá-las em estratégias de ação, sempre levando em conta aspectos referentes à viabilidade e ao valor que será agregado, tendo-se em vista a condição futura de aposentado". Da mesma forma que é discutida a construção do projeto de vida para jovens em início de carreira, é relevante facilitar a elaboração do projeto de vida na transição da aposentadoria, fase essa, que pode trazer mudanças bruscas para uma carreira construída e sólida (Boehs et al., 2017).

O projeto de vida, relacionado ao trabalho ou não, deve ser algo palpável, viável, baseado nos interesses, nas necessidades e no que se quer fazer ou vivenciar. O desenho do programa deve encorajar o indivíduo a estabelecer suas prioridades e prazos para cada etapa, por meio de exercícios grupais e vivências que facilitem a criação, pelos participantes, de seus projetos de vida (França, 2016). A equipe que desenvolve o programa deve estar atenta ainda às fases de mudança do comportamento individual, que envolvem desde o desinteresse pelo processo até o engajamento em ações, para que o projeto de vida possua eficácia (Leandro-França, Murta, \& Villa, 2014).

Paralelamente ao desenvolvimento dos PPA, houve uma ampliação de trabalhos científicos teóricos e empíricos sobre o assunto. Atualmente, os estudos nesse tema estão voltados para reforçar a importância da preparação para a aposentadoria e as principais formas de aplicação e avaliação dos PPA (França, 2016; França \& Soares, 2009), entender os aspectos psicossociais da aposentadoria (França et al., 2013), buscar novas estratégias de planejamento para a aposentadoria (Murta et al., 2014; Zanelli et al., 2010) e aprimorar os instrumentos de avaliação relativos à área (Rafalski \& Andrade, 2017).

A evolução dos estudos da área caminha para o aperfeiçoamento dos programas, porém ainda existem muitas lacunas nessa área de estudo. São apontadas deficiências especialmente nas abordagens experimentais utilizadas, na ausência do uso de instrumentos validados na mensuração, na falta de avaliações longitudinais e de procedimentos robustos de análise dos dados em intervenções voltadas para aposentados (Leandro-França, Murta, Hershey, \& Martins, 2016).

Tais lacunas, associadas aos apontamentos de que nem sempre os PPA têm apresentado sustentabilidade em suas ações, sugerem a necessidade de ampliar a discussão sobre o aperfeiçoamento das práticas realizadas atualmente. Novos modelos devem ser pensados, baseados em reflexões sistemáticas relacionadas à história dos próprios trabalhadores, ao que passaram e ao que gostariam de viver (França et al., no prelo). Neste sentido, consideramos que a Autobiografia Orientada pode ser uma alternativa para a sustentabilidade do PPA e sua expansão extra-organizacional.

\section{A Autobiografia Orientada (GAB)}

A Autobiografia Orientada (GAB) ou Life Portfolio (Birren \& Feldman, 1997; Birren \& Deutchman, 1991) foi idealizada pelo psicólogo e gerontólogo americano Prof. Dr. James Birren (1918-2016), uma proeminente personalidade americana na área do envelhecimento. Birren é autor de inúmeras publicações sobre gerontologia, foi co-fundador do Ether Percy Andrus Gerontology Center (University of Southern California) e diretor associado do Centro de Estudos de Envelhecimento (Universidade da Califórnia [UCLA]). As instituições das quais Birren fez parte ficaram conhecidas por promover a investigação sobre o envelhecimento, mudanças cognitivas e estudos autobiográficos (Americam Society on Aging, 2016).

A GAB é um método de escrita sobre a história de vida que parte do princípio que sempre temos muito a aprender sobre o nosso próprio passado e que revisitá-lo pode ser uma experiência estimulante e enriquecedora. Visando devolver o controle do indivíduo sobre o seu passado, presente e futuro, são utilizadas técnicas de revisão da vida que desencadeiam as memórias mais relevantes sobre assuntos e necessidades dos adultos mais velhos (Birren \& Deutchman, 1991). Na perspectiva de Birren, as interpretações individuais sobre a vida (e não a idade) influenciam o bem-estar e as mudanças de cada um ao longo da vida, pois os indivíduos carregam continuamente consigo suas experiências passadas (Birren, 2006). Assim, mais importante que ter informações objetivas sobre essas experiências, pode ser compreender a interpretação individual sobre elas. A frase "Se você não sabe para onde vai, ao menos saiba onde você esteve" ilustra o ponto de vista utilizado para desenvolver o método (Birren \& Svensson, 2014). 
A GAB foi desenhada para combinar os benefícios da autobiografia com experiências de: (a) interação grupal e liderança; (b) reflexões particulares da vida sobre temas selecionados; e (c) compartilhamento de pensamentos em um grupo de encorajamento (Birren \& Deutchman, 1991). Desde sua criação, ela tem sido amplamente utilizada nos Estados Unidos e em alguns países da Ásia e Europa em diferentes contextos, encontrando resultados positivos (Reker, Birren, \& Svensson, 2014).

Os grupos devem ser desenvolvidos com 10 a 16 pessoas, no mínimo 10 encontros, com duração de aproximadamente duas horas cada. São utilizadas técnicas para revisão da vida visando à retomada do controle do indivíduo sobre o seu passado, presente e futuro. A cada sessão, o grupo trabalha sobre determinado ponto ramificador, que representa eventos, experiências ou as introspecções que deram forma e direção a sua existência, como o casamento ou a aposentadoria, ou eventos pequenos que tiveram grandes resultados, como a leitura de um livro ou escalar uma montanha (Birren \& Deutchman, 1991). O indivíduo é orientado a buscar fatos importantes na sua história pessoal, relacionados aos temas trabalhados semanalmente. Estes temas podem ser adicionados ou substituídos de acordo com as características comuns ao grupo. As temáticas que serão discutidas e refletidas pelos grupos serão pré-definidas pelos participantes, de acordo com o número de sessões a serem realizadas. Ao final, os participantes são estimulados a escrever sobre temas ou pontos ramificadores das suas vidas.

Birren e Feldman (1997) sugerem que nos primeiros encontros seja proposto que os participantes preencham a sua "lifeline", que se trata de um gráfico em que o eixo vertical seja composto de pontuações de $0 \%$ a $100 \%$, dependendo de como a pessoa classifica os eventos da sua vida e um eixo horizontal com a idade em anos. Deve-se desenhar uma linha vertical pontilhada na sua idade atual e com a idade que se espera atingir e conectar os pontos para completar o gráfico da vida. Outra dinâmica inicial que pode ser desenvolvida é solicitar que o participante escreva os componentes da pessoa ideal que gostaria de ser. Para isto, escreverá o nome da pessoa ou personagens de livro ou filme que usou como modelo, tanto positivo quanto negativo, nas seguintes características: aparência, saúde, realizações e outras.

Após a definição dos temas e cronograma dos encontros, o coordenador do grupo tem a função de orientar os participantes sobre a temática da próxima sessão, para que possam desenvolver, como atividade de casa, um texto de até duas páginas. A primeira parte do encontro seguinte consistirá na abordagem do tema desenvolvido em casa por meio de exposições, dinâmicas, vivências ou outras atividades que levem os participantes à discussão. Em seguida, cada um deve ler a sua redação e o grupo pode fazer perguntas sem juízo de valor sobre o que o participante está relatando. Ao final, é aberto novamente um espaço de discussão, onde o facilitador instiga os participantes a pensar em sobre o que gostariam e poderiam realizar de forma diferente da história apresentada. A tarefa do coordenador/facilitador é equilibrar a discussão, permitindo que todos tenham o mesmo espaço para expor seu material e ouvir o relato alheio (Birren \& Deutchman, 1991; Birren \& Feldman, 1997). Após a finalização do encontro, a redação poderá ser detalhada e aperfeiçoada em casa, como se os participantes fossem publicar sua autobiografia (Birren \& Deutchman, 1991; Birren \& Feldman, 1997).

A GAB não é considerada terapia, mas um método que proporciona diversos benefícios, tais como: aprender mais sobre você mesmo, estimular o cérebro, melhorar o bem-estar e criar um legado a partir do momento que escreve sua autobiografia (Birren \& Svensson, 2014; Reker, Birren, \& Svensson, 2014). A revisão da vida, por meio dessas redações, facilita a reconstrução da autoestima, utilizando-se dos pontos ramificadores e interesses priorizados em prazos que os próprios participantes estabelecerão para alcançar seus objetivos. A GAB representa uma oportunidade para melhor entendimento e aceitação de si mesmo e a elaboração de um projeto passível de ser realizado no futuro (Birren \& Deutchman, 1991).

\section{A GAB como Método de Avaliação de Carreira e Planejamento para a Aposentadoria}

A GAB é uma intervenção bem difundida atualmente entre grupos adultos nos Estados Unidos e em outros países (Birren, \& Svensson, 2014; Reker, Birren, $\&$ Svensson, 2014). Dr. Birren esteve no Brasil em 2001 quando ministrou um curso no Rio de Janeiro sobre o uso da Autobiografia Orientada. O primeiro autor deste artigo participou desse curso, e em 2002, teve a oportunidade de realizar uma visita ao grupo do Dr. Birren na Universidade da Califórnia - UCLA (Los Angeles), obtendo o seu aval para utilizar a GAB em PPA no Brasil (França \& Amorim, 2017).

Assim, uma das possibilidades da autobiografia orientada é a sua utilização no apoio aos trabalhadores na transição da aposentadoria, como um método que os ajude no planejamento para que tomem a melhor decisão em função dos seus interesses e consequente bem-estar (França \& Amorim, 2017). O planejamento para a aposentadoria implica em analisar diversos aspectos da vida de cada pessoa que está próxima à decisão, considerando a sobrevivência e o bem-estar no passado, no presente e no 
futuro, o que pode ser contemplado utilizando o método da GAB (França \& Amorim, 2017; França \& Soares, 2009).

França (2016) enfatiza que aquele que está em vias de se aposentar deve obter elementos necessários para gerenciar o seu projeto de vida, administrando as perdas e reforçando os ganhos relacionados a esse momento, em função dos desejos e possibilidades. Essa constatação vem ao encontro do que Birren e Deutchman (1991) afirmaram quanto a compartilhar as histórias de vida com outros membros do grupo estimula algumas memórias de um passado, por vezes negligenciado, permitindo aos indivíduos reviverem partes de si nas histórias dos outros. De acordo com esses autores, os participantes da GAB aprendem a apreciar tanto a sua singularidade e semelhanças com outros e a conhecer mais sobre si num contexto encorajador.

No sentido profissional, o reencontro com a própria carreira e consequente avaliação do que foi vivido na relação com o trabalho podem auxiliar na construção de um planejamento do que se quer alcançar nessa nova etapa da vida (Birren, 2001). Santos e Ferreira (2016) em pesquisa com professores ressaltam a importância da história de vida dos participantes no desenvolvimento profissional dos mesmos. $\mathrm{O}$ acesso às narrativas de vida dos indivíduos permitiu constatar que as vivências pessoais e profissionais moldaram o desenvolvimento de carreira daquele indivíduo (Santos \& Ferreira, 2016). Tais afirmações nos permitem concluir que o projeto de Autobiografia Orientada encontra afinidade com a Orientação Profissional, no que diz respeito a proporcionar ao indivíduo uma reflexão sobre sua relação com o trabalho e com seus projetos futuros (Martins \& Borges, 2017).

Em síntese, para passar por uma mudança tão significativa como a aposentadoria, é fundamental olhar para trás e fazer as pazes com as escolhas do passado, para possibilitar as decisões conscientes no presente, a fim de se construir o futuro desejado (França \& Amorim, 2017). Para realizar a GAB no contexto da aposentadoria, os temas podem ser fixos ou flexíveis e ainda, atender a alguma situação específica do grupo a ser trabalhado. As temáticas são pré-escolhidas, sugeridas pelo facilitador e referendadas pelo grupo, de acordo com a experiência do facilitador e o conhecimento do grupo, bem como o número de sessões disponíveis. Uma sugestão de roteiro que cumpra o objetivo de avaliar a vida pregressa, a carreira e se preparar para uma decisão relacionada a aposentadoria poderia ser:

1. Significado da sua vida - suas aspirações e ambições;

2. História da vida familiar;

3. História da vida educacional;

4. História do trabalho, da carreira e dos interesses no pós-carreira;
5. Relato da imagem que ele/ ela tem do seu próprio corpo;

6. Histórico da sua saúde, principais doenças, cirurgias e estado atual de saúde;

7. Relato da função do dinheiro em sua vida e economias já realizadas;

8. História dos seus amores e ódios;

9. Relato das suas experiências ou ideias sobre a morte;

10. Estabelecimento de metas e aspirações para o futuro - projeto de vida para a aposentadoria.

A fim de avaliar os resultados do programa em curto, médio e longo prazo, é importante que sejam realizadas não apenas avaliações de reação sobre a satisfação dos participantes com relação do método $\mathrm{GAB}$, como também medidas dos resultados esperados. Um critério para essa avaliação poderia ser as medidas de recursos disponíveis para a aposentadoria (Leung \& Earl, 2012), dos motivos para se aposentar e da satisfação com a aposentadoria (Alvarenga, Kiyan, Bitencourt, \& Wanderley, 2009; Floyd et al., 1992; Oliveira, Torres, \& Albuquerque, 2009; Pimenta et al., 2008; Zanelli, 2012). O ideal é que os níveis desses constructos sejam medidos antes do início das sessões da GAB, imediatamente ao final do curso, e após um ano de finalizado o processo. Além disso, análises qualitativas dos conteúdos das biografias dos participantes podem se configurar como um instrumento valioso para avaliação da adequação e aperfeiçoamento do método.

A partir do que foi apresentado, a Autobiografia Orientada se apresenta como opção viável e coerente tanto como método de avaliação da carreira e de construção de projeto de vida, ambos adequados ao PPA. Estudos futuros poderiam implementar essa técnica aplicada a pré-aposentados, comprovando a aplicabilidade através do levantamento de resultados com base nos relatos, no desenvolvimento dos projetos de vida e na percepção de bem-estar dos participantes.

\section{Considerações Finais}

O PPA representa um grande benefício à medida que desenvolve o autoconhecimento dos trabalhadores e oferece apoio nas decisões que afetarão seu futuro. A GAB, por sua vez, significa a sistematização de passos a serem dados em direção a novas reflexões sobre a longevidade e o que precisa ser realizado para melhor vivê-la.

De modo geral, independentemente do termo utilizado quer seja a preparação, orientação ou educação para a aposentadoria, o que de fato interessa é ressaltar a necessidade do planejamento não apenas para quem está se aposentando, mas para a organização estruturar melhor 
seu quadro de pessoal, facilitar a inclusão dos trabalhadores mais velhos, favorecer a intergeracionalidade entre as equipes de trabalho, proporcionar as capacitações para os mais jovens e atualizações necessárias aos mais velhos (França et al., 2014).

Ao investir nos programas de preparação, o empregador tem como retorno tanto o sucesso na aposentadoria daquele que sai da organização, quanto a motivação do trabalhador mais velho, que, ao permanecer mais satisfeito na empresa, tende a aumentar a produtividade até o seu desligamento. Já para o trabalhador mais jovem, o PPA representa a segurança de trabalhar em uma empresa que não está apenas preocupada com o lucro imediato, mas tem interesse na vida e bem-estar dos seus funcionários e na construção de uma parceria em longo prazo. Por permear os eventos passados, presentes e futuros dos indivíduos, esse é um tema de interesse de todas as idades (França, 2016).

Apesar da pertinência do PPA, é importante ressaltar que não apenas as organizações precisam propor planos de aposentadoria para todos os seus colaboradores, como estes também devem ser estimulados a assumirem individualmente a responsabilidade pelo seu projeto de vida. Independente da forma como ocorrer, a preparação deve estimular um planejamento para o futuro, uma reflexão sobre a carreira construída até então e sobre o projeto de vida que se quer desenhar.
O que se almeja é abranger formas e estratégias de como lidar com as perdas e as desvantagens da aposentadoria, bem como valorizar os ganhos a serem conquistados, seja por meio da manutenção dos recursos e interesses, da recuperação de antigos projetos ou da elaboração de um novo script de vida. Estudos internacionais já comprovaram os efeitos positivos do planejamento, como a manutenção da saúde física e psicológica, diminuição da ansiedade e satisfação com a aposentadoria (Wang \& Shi, 2013; Yeung, 2013), e algumas evidências brasileiras foram apresentadas capazes de reforçar a implantação e continuidade do PPA para todas as organizações (Murta, et al., 2014).

O planejamento da aposentadoria deve ser visto como um processo de educação continuada que precisa estar relacionado a um projeto de vida. Esta é uma responsabilidade dos governos, devolvendo políticas e propostas que contemplem esse desafio; das organizações, oferecendo suporte a seus colaboradores; da sociedade, reconhecendo o valor e entendendo a delicadeza desse momento transição; e de todos nós, nos responsabilizando pelos nossos próprios planejamentos. Ações em todas essas esferas, que sejam realizadas de forma interligada entre si, certamente contribuem para a construção de um envelhecimento bem sucedido.

\section{Referências}

Alvarenga, L. N., Kiyan, L., Bitencourt, B., \& Wanderley, K. S. (2009). Repercussões da aposentadoria na qualidade de vida do idoso. Revista da Escola de Enfermagem da USP, 43(4), 796-802. DOI: 10.1590/S0080-62342009000400009

Americam Society on Aging. (2016). In Memory of James (Jim) E. Birren. Recuperado em 28 fevereiro 2018, de http:// www.asaging.org/blog/memory-james-jim-e-birren

Banco Mundial. (2016). World Bank Open Data by country. Recuperado em 28 fevereiro 2018, de http://data.worldbank. org/country/brazil?view=chart

Birren, J. (2001). Relembrar a Vida Melhora a Autoestima. [Entrevista com Mirna Feitoza- Free-Lance Folha de São Paulo]. Recuperado em 28 fevereiro 2018, de http://www1.folha.uol.com.br/fsp/equilibrio/eq0208200106.htm

Birren, J. (2006). How do I think I got there? The LLI Review, Fall 2006. Recuperado em 28 fevereiro 2018, de http://nrc. northwestern.edu/

Birren, J., \& Deutchman, D. E. (1991). Guiding autobiography groups for older adults: Exploring the fabric of life. Baltimore: The Johns Hopkins University Press.

Birren, J., \& Feldman, L. (1997). Where to Go from Here? Discovering Your Own Life's Wisdom in the Second Half of Your Life. New York: Simon \& Schuster.

Birren, J. E., \& Svensson, C. M. (2014).Guided autobiography: Writing and telling the stories of lives. The LLI Review, 1, 113-119. Recuperado 28 fevereiro 2018, de https://static1.squarespace.com/static/55bbbafce4b08dd9a4e4994e/t/ 56da3c503c44d8dcc8477608/1457142864640/OsherArticleFinal+.pdf

Boehs, S. de T. M., Medina, P. F, Bardagi, M. P., Luna, I. N., \& Silva, N. (2017). Revisão da literatura latino-americana sobre aposentadoria e trabalho: Perspectivas psicológicas. Revista Psicologia Organizações e Trabalho, 17(1), 5461. DOI: $10.17652 /$ rpot/2017.1.11598

Brasil. (1994). Lei n 8.842, de 4 de janeiro de 1994. Dispõe sobre a Política Nacional do Idoso, cria o Conselho Nacional do Idoso e dá outras providências. Diário oficial da União. 
Brasil. (2003). Lei no 10.741, de 1 de outubro de 2003. Dispõe sobre o Estatuto do Idoso e dá outras providências. Diário oficial da União.

Floyd, F. J., Haynes, S. N., Doll, E. R. Winemiller, D., Lemsky, C., Burgy, T. M., Werle, M., \& Heilman, N. (1992). Assessing retirement satisfaction and perceptions of retirement experiences. Psychology and Aging, 4(2), 609-621. DOI: $10.1037 / 0882-7974.7 .4 .609$

França, L. H. F. P. (2016). Programas de Preparação para a Aposentadoria: Diagnóstico e Estratégias para Implantação. In: Mendonça, H., Ferreira, M. C. \& Neiva, E. R. (Orgs.) Análise e Diagnóstico Organizacional. São Paulo: Vetor.

França, L. H. F. P., \& Amorim, S. M. (2017). Guided autobiography as a method for retirement preparation program. MOJ Gerontology \& Geriatrics, 2(1). DOI: 10.15406/mojgg.2017.02.00042

França, L. H. F., Amorim, S. M., Siqueira- Brito, A. R., Medeiro, S. A., Souza, A. P.,\& Leite, S. V. (no prelo). Perfil dos programas de preparação para a aposentadoria em empresas públicas e privadas brasileiras. Revista de Estudos Interdisciplinares sobre o Envelhecimento.

França, L. H. F. P., Bendassolli, P., Menezes, G. S., \& Macedo, L. (2013). Aposentar-se ou continuar trabalhando? O que influencia essa decisão? Psicologia: Ciência e Profissão, 33, 548-563. DOI: 10.1590/S1414-98932013000300004.

França, L. H. F. P., Nalin, C. P., Siqueira-Brito, A. R., Amorim, S. M., Rangel, T., \& Ekman, N. C. (2014). A percepção dos gestores brasileiros sobre os programas de preparação para a aposentadoria. Estudos Interdisciplinares sobre Envelhecimento, 19(3), 879-898. Recuperado em 28 fevereiro 2018, de http://www.seer.ufrgs.br/RevEnvelhecer/ article/view/50434

França, L. H. F. P., \& Soares, D. H. P. (2009). Preparação para a aposentadoria como parte da educação ao longo da vida. Psicologia: Ciência e Profissão, 29(4), 738-751. DOI: 10.1590/S1414-98932009000400007

França, L. H. F. P., \& Vaughan, G. (2008). Ganhos e perdas: Atitudes dos executivos brasileiros e neozelandeses frente à aposentadoria. Psicologia em Estudo, 13(2), 207-216. DOI: 10.1590/S1413-73722008000200002

Froidevaux, A., Baumann, I.,Maggiori, C., Wieber, F., \& Rossier, J. (2017). Retirement planning: How to deal with different adjustment trajectories? In B. J. Ertelt, \& M. Scharpf, (Eds.) Career Guidence for Older Workers, (pp.25-53) New York: Peter Lang.

Henkens, K., van Dalen, H., Ekerdt, D.J., Hershey, D. A., Hyde, M., Radl, J., van Solinge, H., \& Wang, M., Zacher, H. (2017). What we need to know about retirement: Pressing issues for the coming decade. The Gerontologist, gnx095. DOI: $10.1093 /$ geront/gnx095

Instituto Brasileiro de Geografia e Estatística. (2017). Tábua completa de mortalidade para o Brasil-2016. Recuperado em 28 fevereiro 2018, de ftp://ftp.ibge.gov.br/Tabuas_Completas_de_Mortalidade/Tabuas_Completas_de_Mortalidade_2016/ tabua_de_mortalidade_analise.pdf

Instituto de Pesquisa Econômica Aplicada. (2016). Política nacional do idoso: Velhas e novas questões. Rio de Janeiro. Recuperado em 28 fevereiro 2018, de http://repositorio.ipea.gov.br/handle/11058/7253

Kim, N., \& Hall, D. T. (2013). Protean career model and retirement. In Wang, M. (Ed.) The Oxford Handbook of Retirement (pp. 102-116). Oxford: Oxford University Press.

Leandro-França,C., Murta, S. G.,Hershey,D., \& Martins, L.(2016). Evaluation of retirementplanning programs:Aqualitative analysis of methodologies and efficacy. Educational Gerontology, 42, 1-39. DOI: 10.1080/03601277.2016.1156380

Leandro-França, C., Murta, S. G., \& Villa, M. B. (2014). Effects of brief intervention in planning for retirement. Revista Psicologia Organizações e Trabalho, 14(3), 257-270. DOI: 10.4025/psicolestud.v20i4.27413

Leung, C. S. Y., \& Earl, J. K. (2012). Retirement Resources Inventory: Construction, factor structure and psychometric properties. Journal of Vocational Behavior, 81, 171-182. DOI: 10.1016/j.jvb.2012.06.005

Martins, L. F., \& Borges, E. S. (2017). Educação para aposentadoria: avaliação dos impactos de um programa para melhorar a qualidade de vida pós-trabalho. Interações, 18(3), 55-68. DOI: 10.20435/inter.v18i3.1496.

Murta, S. G., Abreu, S., Leandro-França, C., Pedralho, M., Seidl, J., Lira, N. P. M., Carvalhedo, R. K. M., Conceição, A. C., \& Gunther, I. A. (2014). Preparação para a aposentadoria: Implantação e avaliação do programa viva mais! Psicologia: Reflexão e Crítica, 27(1), 01-09. DOI: 10.1590/S0102-79722014000100001

Oliveira, C., Torres, A. R. R., \& Albuquerque, E. S. (2009). Análise do bem-estar psicossocial de aposentados de Goiânia. Psicologia em Estudo, 14(4), 749-757. DOI: 10.1590/S1413-73722009000400015

Organização Mundial de Saúde (2015). Relatório Mundial de Envelhecimento e Saúde. Recuperado em 28 fevereiro 2018, de http://sbgg.org.br/wp-content/uploads/2015/10/OMS-ENVELHECIMENTO-2015-port.pdf 
Pazzim, T. A., \& Marin, A. (2016). Programas de Preparação para Aposentadoria: Revisão sistemática da literatura nacional. Revista Brasileira de Orientação Profissional, 17(1) 91-101. Recuperado em 28 fevereiro 2018, de http:// pepsic.bvsalud.org/pdf/rbop/v17n1/10.pdf

Pimenta, F. A. P., Simil, F. F., Tôrres, H. O. G., Santos, C. F., Amaral, C. F. R., Coelho, T. O., \& Rezende, N. A. (2008). Avaliação da qualidade de vida de aposentados com a utilização do questionário SF-36. Revista da Associação Médica Brasileira, 54(1), 55-60. Recuperado em 28 fevereiro 2018, de http://www.repositorio.ufop.br/ handle/123456789/5821

Rafalski, J. A., \& Andrade, A. L. (2017). Desenvolvimento da escala de percepção na aposentadoria. Psico-USF, 22(1), 49-62. DOI: 10.1590/1413-82712017220105

Reker, G. T., Birren, J., \& Svensson, C. (2014). Self-aspect reconstruction through guided autobiography: Exploring underlying processes. The International Journal of Reminiscence and Life Review, 2(1), 1-15. Recuperado em 28 fevereiro 2018, de http://www.ijrlr.org/ojs/index.php/IJRLR/article/view/41

Santos, J. R., \& Ferreira, L. G. (2016). Desenvolvimento profissional, vida e carreira: história de professores atingidos pelo mal-estar docente. Revista Educação e Emancipação, 9(2), 108-137. DOI: 10.18764/2358-4319.v9n2p108-137

Taylor, M. A., \& Schaffer, M. (2013). Planning and adaptation to retirement: The post-retirement environment, change management resources, and need oriented factors as moderators. In M. Wang (Ed.), The Oxford Handbook of Retirement (pp. 249-267). Oxford: Oxford University Press.

Wang, M., \& Shi, J. (2013). Psychology Research on Retirement. Annual Review of Psychology, 65, 209-233. DOI: 10.1146/annurev-psych-010213-115131

Yeung, D. Y. (2013). Is pre-retirement planning always good? Na exploratory study of retirement adjustment among Hong Kong Chinese retirees. Aging \& Mental Health, 17(3), 386-393. DOI: 10.1080/13607863.2012.732036

Zanelli, J. C. (2012). Processos Psicossociais, bem-estar e estresse na aposentadoria. Revista Psicologia Organizações e Trabalho, 12(3), 329-340.

Zanelli, J. C., Silva, N., \& Soares, D. H. P. (2010). Orientação para Aposentadoria nas Organizações de Trabalho: Construção de Projetos para o Pós-carreira. Porto Alegre: Artmed.

Recebido: 10/10/2017

$1^{a}$ reformulação: 01/02/2018

Aceite final: 03/02/2018

Sobre as autoras

Lucia Helena de Freitas Pinho França é PhD pela The University of Auckland (NZ), psicóloga, professora do Programa de Pós-Graduação em Psicologia (PPGP) da Universidade Salgado de Oliveira (UNIVERSO).

Silvia Miranda Amorim é psicóloga, mestre em psicologia e doutoranda em Psicologia pelo Programa de PósGraduação em Psicologia (PPGP) da Universidade Salgado de Oliveira (UNIVERSO).

Andreia Pereira de Souza é psicóloga, mestranda em Psicologia pelo Programa de Pós-Graduação em Psicologia (PPGP) da Universidade Salgado de Oliveira (UNIVERSO).

Thais Cravo Schuabb é psicóloga, mestranda em Psicologia pelo Programa de Pós-Graduação em Psicologia (PPGP) da Universidade Salgado de Oliveira (UNIVERSO). 